\title{
Uncertainty and Dissent in Climate Risk Assessment: A Post-Normal Perspective
}

\author{
Jeroen P. van der Sluijs
}

\begin{abstract}
Uncertainty complexity and dissent make climate change hard to tackle with normal scientific procedures. In a post-normal perspective the normal science task of "getting the facts right" is still regarded as necessary but no longer as fully feasible nor as sufficient to interface science and policy. It needs to be complemented with a task of exploring the relevance of deep uncertainty and ignorance that limit our ability to establish objective, reliable, and valid facts. This article explores the implications of this notion for the climate science policy interface. According to its political configuration the Intergovernmental Panel on Climate Change (IPCC) adopted a "speaking consensus to power" approach that sees uncertainty and dissent as a problematic lack of unequivocalness (multiple contradictory truths that need to be mediated into a consensus). This approach can be distinguished from two other interface strategies: the "speaking truth to power approach," seeing uncertainties as a temporary lack of perfection in the knowledge (truth with error bars) and the "working deliberatively within imperfections" approach, accepting uncertainty and scientific dissent as facts of life (irreducible ignorance) of which the policy relevance needs be explored explicitly. The article recommends more openness for dissent and explicit reflection on ignorance in IPCC process and reporting.
\end{abstract}

\section{KEYWORDS}

consensus, controversy, dissent, Intergovernmental Panel on Climate Change (IPCC), post-normal science, science-policy interface, uncertainty

\section{Introduction}

Anthropogenic climate change is a complex and contested issue. The earth with its oceans, continents and islands, atmosphere, biosphere, ice masses and water currents, carbon, nitrogen and countless other substances, forms an extremely complex system in which numerous interactions are at work. Many of its partial systems and underlying processes are still poorly understood. Exploring the consequences of human influences on that system and by extension the climate is 
therefore possible to a limited extent only. Still, enough is known to give reason for concern, and it is precisely for that reason that policymakers greatly need to have good comprehensive scientific assessments of the climate issue (Van der Sluijs and Turkenburg 2006).

Climate change has many characteristics that make it hard to tackle with normal scientific procedures. It requires new ways of interfacing science and policy (Funtowicz 2006; Van der Sluijs 1997, 2010). Funtowicz and Ravetz (1993) have called this class of problems post-normal, where "normal" refers to Kuhn's 1962 concept of normal science. Kuhn describes normal science both as "a strenuous and devoted attempt to force nature into the conceptual boxes supplied by professional education" (Kuhn 1962: 5) and as the practice of uncritical puzzle solving within an unquestioned framework or "paradigm." Funtowicz and Ravetz (1986, 1990, 1993) signalized that such a normal science approach runs into serious limitations when addressing societal issues (in that time nuclear reactor safety) where scientific evidence is highly contested and plagued by uncertainties. At the same time decisions need to be made well before conclusive supporting evidence can be available and decision stakes are high: the potential impacts of wrong decisions can be huge. In such situations actors tend to strongly disagree on the values that should guide the decision making, for example solidarity or economic growth. The available knowledge bases are typically characterized by imperfect understanding (and imperfect reduction into models) of the complex systems involved. Models, scenarios, and assumptions dominate assessment of these problems, and many (hidden) value loadings reside in problem frames, indicators chosen, and assumptions made.

The science involved in such issue-driven integrated assessments of complex environmental issues differs substantially from the practice of normal science in curiosity-driven laboratory research. Risk assessment of anthropogenic climate change involves uncertainties of many sorts, not all of which can be tamed. We cannot perform a statistically satisfying series of reproducible experiments to test the effect of higher atmospheric greenhouse gas concentrations, because there is only one Earth available, and even the one available is poorly monitored. In addition, other factors that influence climate are-in contrast to the situation in a laboratory-largely beyond our control. Scientific assessments of climate change are unavoidably based on a mixture of knowledge, assumptions, models, scenarios, extrapolations, and known and unknown unknowns. Because of the limited knowledge base, scientific assessments will unavoidably use expert judg- 
ments and subjective probability judgments. It comprises bits and pieces of knowledge that differ in status, covering the entire spectrum from well-established knowledge to judgments, educated guesses, tentative assumptions, and even crude speculations (Van der Sluijs et al. 2005, 2008). Research on climate change comprises a large variety of scientific disciplines leading to the well-known problem that when quantitative information is produced in one disciplinary context and used in another, important caveats tend to be ignored, uncertainties compressed, and numbers used at face value (Van der Sluijs et al. 1998). This poses additional requirements with regard to the systematic analysis, documentation, and communication of uncertainty. Knowledge utilization for environmental risk governance requires a full and public awareness of the various sorts of uncertainty and underlying assumptions. Knowledge needs to be robust both technically and socially. All this implies a key role for knowledge quality assessment. As Funtowicz and Ravetz (1990: 1) phrased it: "The issue of quality control in science, technology and decision-making is now appreciated as urgent and threatening. The experiences of Chernobyl and Challenger, both resulting from lapses of quality control, illustrate this problem. We have described the 'Ch-Ch Syndrome': the catastrophic collapse of sophisticated mega-technologies resulting from political pressure, incompetence and cover-ups."

Post-normal science is a reflective approach to interface science and policy in complex situations as sketched above. It is based on three defining features (Funtowicz and Ravetz 1993; Petersen et al. 2011; Ravetz 1999; Van der Sluijs et al. 2008):

- The management of uncertainty. Post-normal science acknowledges that uncertainty is more than a technical number-range or methodological issue. Ambiguous knowledge assumptions and ignorance give rise to epistemological uncertainties;

- The acknowledgement of a plurality of legitimate perspectivesboth cognitive and social. Complex problem solving requires scientific teamwork within an interdisciplinary group and joint efforts by specialists from the scientific community and from business, politics, and society. Scientists from different backgrounds often have irreconcilable and conflicting yet tenable and legitimate scientific interpretations of the same body of scientific evidence;

- The management of quality. An extended peer community includes representatives from social, political, and economic do- 
mains who openly discuss on various dimensions of uncertainties, strengths, weaknesses, and ambiguities in the available body of scientific evidence and its implications for all stakeholders with respect to the issue at hand.

Where in normal science the key task in interfacing science and policy is to get the facts right, in post-normal science this is complemented with a new key task of exploring the relevance of deep uncertainty and ignorance that limit our ability to establish objective, reliable, and valid facts (see also Funtowicz 2006; Van der Sluijs et al. 2010a, 2010b). In post-normal problem solving, scientific fact-finding is still regarded as necessary but no longer sufficient. Scientific facts have become "soft" in the context of the "hard" value commitments that will determine the success of policies (Funtowicz and Ravetz 1993).

In the following I explore the science-policy interface with regard to anthropogenic climate change and reflect on the degree to which the post-normal characteristics such as uncertainty, high stakes, and dissent are acknowledged and whether post-normal approaches have been adopted in the practice of the main science-policy interface organization for climate science: the Intergovernmental Panel on Climate Change (IPCC). I end with recommendations on how the practice of interfacing climate science and climate policy can gain from the insights from the field of post-normal science.

\section{The Emergence of the Climate-Science-Policy Interface}

Man has been studying the climate for centuries. The fact that naturally occurring atmospheric greenhouse gases such as $\mathrm{CO}_{2}$ play a role in the infrared balance of the earth and thus in the climate has been known since work of Joseph Fourrier (1768-1830) (see Van der Sluijs 1997). The first few centuries of climate research focused on explaining weather fluctuations in the geological past, like the ice ages. Scientific research into climate change due to human actions is however a relatively new research area. In 1908 Alfred Lotka issued the first scientific warning, foreseeing far-reaching climatologic impacts if the large-scale use of coal continued (Pilson 2006). It was not until the 1980s that politicians and policymakers started becoming interested in the issue of climate change and thus needing more scientific knowledge about it (Social Learning Group 2001). This created a demand for policy-oriented climate science. 
In the late 1980s there were many scientific studies about causes and consequences of climate change, which partially contradicted each other and of which the exact relevance in terms of policy was not clear. To arrive at international agreements about climate policy, policymakers needed a carefully weighed overview of the state of knowledge in the field of climate change. In 1988 the IPCC was established as an independent scientific panel by the United Nations Environment Program (UNEP) together with the World Meteorological Organization (WMO). The IPCC is an intergovernmental agency and is open to all member states of the United Nations and the WMO. Government representatives participate in the IPCC review procedures and in the plenary meetings where the program of activities is determined and reports prepared, and where the IPCC staff and its chairman are elected.

The role of the IPCC is formally established to assess on a comprehensive, objective, open, and transparent basis the scientific, technical, and socio-economic information relevant to understanding the scientific basis of risk of human-induced climate change, its potential impacts, and options for adaptation and mitigation. IPCC reports have to be neutral with respect to policy, although they might need to deal objectively with scientific, technical, and socio-economic factors relevant to the application of particular policies (IPCC 2006). Its mandate comprises mapping out the scientific basis for climate change, and its task includes listing socio-economic factors that are relevant for the implementation of specific policies. This involves, for example, exploring the consequences for man, nature and the economy of different possible quantitative long-term end goals of the United Nations Framework Convention on Climate Change. Within its mandate the IPCC can investigate what the consequences are of, say, 1, 2, 3, 4, 5, or 6 degrees of warming worldwide, but may not make pronouncements about which of those possible end goals of the Framework Convention is desirable. The latter is the domain of politics.

The IPCC itself does not carry out new research, but inventories research published in scientific journals and other scientific studies published in books, reports, and databases. This process, in which scientific knowledge is analyzed by experts and adapted in order to inform the policymaking process, is known as an assessment. The knowledge comes from a large number of specialized fields. In an assessment this information is gathered, analyzed, structured, combined, interpreted, and summarized. This knowledge is then presented in such a way that it becomes as understandable, accessible, 
relevant, and useful as possible for anyone who is involved in the policymaking process but is not an expert himself (Parson 1995).

By mapping out scientific consensus, the IPCC fulfills a central political function in certifying robust knowledge that can serve as a foundation for the social and political debate. In international as well as national climate policies, IPCC reports are widely accepted as the most important scientific basis for policymaking. Every five or six years the IPCC publishes an overview of the state of knowledge. In 1990 the IPCC brought out its first assessment report, which was followed by supplements in 1992 and 1994. In 1995 the IPCC brought out its Second Assessment Report (SAR). Since the SAR, IPCC reports have been accepted by the Conference of Parties (COP, the 192 countries that signed the Framework Convention) as scientific starting points to implement the Framework Convention. In 2001 the third assessment report was published and in 2007 the fourth, generally known as AR4.

Each report consists of three partial reports. Partial report I covers the physical science basis (climate system and causes), report II discusses impacts, adaptation and vulnerability, and report III looks at mitigation (possibilities to tackle the causes). Each partial report has a technical summary as well as a summary for policymakers. There is also a synthesis report that summarizes the findings of the three partial reports in general terms. Scientists and government representatives negotiate the content of the summaries for policymakers line by line, where government representatives decide about approval and scientific authors have a veto right of sorts. The fact that all participating governments formally accept the reports of the IPCC and determine policy summaries together with scientists ensures that these reports can count on wide support from governments and policymakers and are considered to be an authoritative source (Petersen 2006).

In general terms, the essence of the main insights of the consecutive IPCC reports and its predecessors of the past thirty years has not changed (see also Clark and Jäger 1997). There is wide agreement among climate scientists about the following items:

- The composition of the atmosphere, especially its concentrations of natural greenhouse gasses, plays a key role in the temperature on the earth surface. Without an atmosphere it would be 33 degrees colder on Earth. The largest part of that difference is due to the natural greenhouse effect coming mainly from water vapor, $\mathrm{CO}_{2}$ and several other trace gasses like methane and nitrous oxide; 
- The observed increase of concentrations of greenhouse gasses in the atmosphere, which has been taking place since the beginning of the industrial revolution, can alter atmospheric and oceanic heat balances in such a way that it causes the climate to change;

- This rise in greenhouse gasses is very probably caused primarily by the increasing use of fossil fuels and by large-scale deforestation;

- When $\mathrm{CO}_{2}$ concentrations double compared to pre-industrial levels, the average Earth surface temperature worldwide will increase by about 1.5 to $4.5^{\circ} \mathrm{C}$. Scenario studies anticipate that in case of unchanged policies, such a doubling will occur in the course of the twenty-first century;

- The tempo and degree of climate change can be influenced to a large extent by technically feasible emission-reduction measures for these gasses.

The first IPCC assessment report (1990) has been mainly of a signaling nature, and it placed the climate problem high up on the policy agenda. The report indicated that there were still many scientific uncertainties, especially about whether the expected anthropogenic effect on the climate could already be observed and which part of the observed temperature increase could be attributed to man. The expected warming through the measured increase of greenhouse gasses was actually smaller than natural variations in climate: climate is never constant, it fluctuates around an average. This problem is known as the signal-to-noise ratio when detecting a signal. The expected signal was so weak that it got lost in the noise. The concern is mainly about the future. For continued emissions of greenhouse gasses the IPCC scenario studies from 1990 anticipated that atmospheric greenhousegas concentrations would become so high so quickly that human influence on the climate would soon far exceed natural variability.

The second assessment report concluded that the balance of evidence suggests a discernible human influence on global climate (IPCC 1996). The use of new detection techniques such as the so-called fingerprint method played an important role here: the various causes of climate change, such as the sun, greenhouse gasses, and carbon emissions from volcanoes, each show a different typical vertical warming pattern ("fingerprint") at different atmospheric altitudes. The third assessment report (2001) concluded even more peremptorily: "There is new and stronger evidence that most of the warming observed over 
the last 50 years is attributable to human activities" (IPCC 2001). In the most recent assessment report, AR4, the conclusion is even more decisive: "Most of the observed increase in global average temperatures since the mid-20th century is very likely due to the observed increase in anthropogenic greenhouse gas concentrations. This is an advance since the Third Assessment Report (TAR)'s conclusion that "most of the observed warming over the last 50 years is likely to have been due to the increase in greenhouse gas concentrations. Discernible human influences now extend to other aspects of climate, including ocean warming, continental-average temperatures, temperature extremes and wind patterns" (IPCC 2007).

How widely shared is the IPCC interpretation in the wider scientific community? Oreskes $(2004,2007)$ investigated the correspondence between climate scientists in scientific publications for the period between 1993 and 2003. She searched for the key phrase "global climate change" in Web of Science and found 924 articles whose abstracts she analyzed. She classified the publications into six categories: explicit confirmation of the IPCC consensus position; evaluation of climatologic impacts; mitigations options; methods; paleontological climate analysis; and rejection of the IPCC consensus position. Of all papers, 75 percent were about the first three categories and subscribed to the IPCC consensus implicitly or explicitly, and the rest were about method or paleontological climate research without taking a position with regard to the role of man in climate change. None of the publications rejected the IPCC consensus position; Oreskes also determined that none of the publications presented data that conflicted with this position. In criticisms of the Oreskes study, we find that Peiser (2005) claims that her approach exaggerated the degree of consensus, and Pielke (2005) considers she does not do enough justice to the diversity of scientific visions on the climate issue.

In a recent study (Doran and Kendall Zimmerman 2009), the degree of consensus in climate science is investigated by a survey among a wide group of scientists. Of the 10,257 addressed scientists, 3,146 answered the questions. To the first question, "When compared with pre-1800s levels, do you think that mean global temperatures have generally risen, fallen, or remained relatively constant?" 90 percent answered that temperatures on the earth had risen. The second question, "Do you think human activity is a significant contributing factor in changing mean global temperatures?" got a positive answer from 82 percent of respondents. When scientists were classified according to degree of expertise it appeared that a higher percentage answered 
"yes" the more specialized they were in the field of climate change. Those scientists who recently published more than half of their studies in scientific journals on the climate topic scored the highest: 97.4 percent of the respondents in that group answered yes to the second question. Non-climatologists who themselves did not publish about the climate in scientific journals scored the lowest, with 76 percent of them seeing a human role in climate change. To compare: in an opinion survey among the American public only 58 percent answered this question positively. The consensus is thus very high, mainly among specialists who have published a lot of research about climate change.

Within mainstream climate science the scientific discussions are not so much about the question of whether man influences the climate but about uncertainties within the climate system. There are thus ranging debates about the relative importance of different factors that contribute to climate change at a specific moment it time, about the exact climatologic processes in the distant past, and about the best way to simulate cloudiness in climate models (see Van der Sluijs et al. 2010a for a detailed account of these issues of dissent).

\section{The Politicization of Climate Science}

In recent years polarization and politicization can be observed, especially in the public debate over the climate problem, in which a group of scientists is very critical of the pronouncements of the IPCC. These scientists profile and organize themselves as "climate skeptics." The political polarization within climate science was well illustrated in March 2009, when the International Alliance of Research Universities held a scientific congress in Copenhagen-Climate Change: Global Risks, Challenges and Decisions - with more than 2,000 participants. The goal was to bring together the latest developments in climate research since AR4. At the same moment, climate skeptics held a counter-congress in New York-Global Warming, Was It Ever Really a Crisis?-in which nearly 800 scientists, journalists and other interested parties participated. The initiator of this congress was the American Heartland Institute. While the university scientists were assessing the new studies as even more alarming than AR4 in Copenhagen (Richardson et al. 2009), the message from New York was that the climate problem was being grossly overestimated, therefore government interventions could not be justified (Heartland 2009). This is where the insights of climate skeptics differ from those of mainstream cli- 
mate scientists and the IPCC over the panel's main conclusion about climate change. Among the issues of contention was the question of whether Earth has become warmer in the past century and whether man has played an important role in that process.

In Canada, ten scientists published their own policymakers' summaries of AR4 under the auspices of the Fraser Institute, called the Independent Summary for Policymakers (McKitrick 2007). The Fraser Institute promotes individual prosperity and the free market, and is opposed to all forms of government intervention.

The somewhat comparable American Heartland Institute published two reports about climate change with the provocatively chosen subtitle Report of the Nongovernmental International Panel on Climate Change (NIPCC) (Idso and Singer 2009; Singer 2008). According to its own website (www.heartland.org) the Heartland Institute is a non-profit organization that puts its energy toward a free market, deregulation and privatization of public facilities, and is against all forms of government intervention and bureaucracy. It can be seen as the opposite pole of an organization such as the United Nations, which the IPCC is partially under. The report from 2008, edited by the American climate scientist Fred Singer, is titled Nature, Not Human Activity Rules the Climate. It is based on a contribution of twenty-five scientists of very contrasting disciplines. Thirty-nine scientists contributed to the 2009 report Climate Change Reconsidered.

The Heartland reports posit that the actual warming is lower than the IPCC concludes, and substantiates this conclusion with a different weighing of data sources (satellite measurements compared to ground measurements) and a different interpretation of some of the same satellite measurements. These reports also state that human influence on the climate is negligible because a certain part of the expected fingerprint based on models was not clearly observable in a specific measurement set. The Heartland Institute states that global warming in the twentieth century is not exceptional and that comparable warming in the geological past was not accompanied by catastrophes. Their reports go into an extensive discussion about shortcomings of simulation models used in climate research, and affirm that stabilizing, natural reactions are being strongly underestimated. The Heartland Institute embraces the hypothesis that interaction between solar activity and cosmic radiation constitutes a more important explanation for the observed warming than the emission of greenhouse gasses caused by man. It also expounds the advantages of warming and higher $\mathrm{CO}_{2}$ concentrations for agriculture and nature through for 
example the $\mathrm{CO}_{2}$ fertilization effect: plants grow more if there is more $\mathrm{CO}_{2}$, and they are more frugal with water if the stomas have to open less often to "breathe in" the same amount of carbon dioxide.

Unlike the IPCC reports, the Heartland reports are not based on a very wide spectrum of available scientific studies. The reports present mainly studies that relativize or contradict the main conclusions of the IPCC. That may be a useful contribution to the scientific debate over climate change, but does put the reports of both institutes in entirely different categories. The Heartland reports should be understood as a form of counter-expertise. The controversy between Heartland and IPCC also shows that the ideological field of tension between free market and government intervention-after all, IPCC reports are part of the legitimation of climate-influencing government policies-is increasingly intruding into the domain of science.

What we see in the climate change controversy is a more generic phenomenon well studied in the broader domains covered by Sociology of Scientific Knowledge (SSK). When the stakes are high in political decisions that are based on scientific studies, the scientific debate becomes politicized (Irwin 2001; Jasanoff et al. 1995; Jasanoff and Wynne 1998). Sometimes societal players deliberately deploy certain tactics to turn scientific results in their favor, to bring a favorable study to the fore, or to be rid of inconvenient knowledge (Avery 2010, 2011; Oreskes and Conway 2010). Peter Gleick (2007) distinguishes a number of categories of tactics that are deployed to such ends for political motives, but which scientifically speaking are improper or misleading, or which abuse the scientific process for spurious goals. The main tactics include: appealing to emotions; making personal (ad hominem) attacks; deliberately mischaracterizing an inconvenient argument and then wiping the floor with the mischaracterized version; inappropriate generalization; misuse of facts and uncertainties; false appeal to authority; hidden value judgments; scientific misconduct, such as selectively leaving out inconvenient measurement results or packing advisory boards (see Michaels 2005).

The climate issue is a textbook example of this. For years now climate skeptics, especially in the United States, have been accused of deploying such tactics with the political motivation of preventing the government from implementing climate policies (McCright and Dunlap 2003). Recently, Hoggan (2009) exposed the strategy of lobbyists for the oil and coal industry in the United States and Canada, linking their close connections with some of the climate skeptics in the US. Oreskes and Conway (2010) presented an illuminating analysis of 
strategies of industrial lobby groups to discredit unwelcome knowledge and manufacture doubt and scientific uncertainty to safeguard profit and vested interests. In recent years the IPCC increasingly came under political fire. In November 2009 unidentified persons hacked into the e-mail correspondence of prominent climate researchers of the University of East Anglia and put it on the Internet (an incident widely referred to as Climategate). Because of the tone and content of some of the hacked e-mails, as well as the discussions that started in early 2010 about found and alleged faults in parts of the most recent IPCC report, questions have risen about the scientific integrity, scrupulousness, and political independence of the IPCC (Van der Sluijs et al. 2010b). The question was brought up of whether the IPCC had organized the production of its reports well, and to what degree these scientific reports are politically tainted. Could their presentation of the knowledge be working in favor of the policy preferences of the involved researchers?

Politicians demanded an evaluation of the work of the panel. To this end, on request of the IPCC the InterAcademy Council (IAC) evaluated the panel's procedures that led to the fourth assessment report in 2007. IAC's main advice is that IPCC should improve its communication and crisis management and should fundamentally reform its management structure and strengthen its procedures to better meet the challenges of increasingly complex climate assessments in a context of more intense public scrutiny of the scientific justifications for climate policies (InterAcademy Council 2010).

\section{IPCC Practice of Coping with Uncertainty and Dissent}

The strategic roles and dynamics of such scientific controversies in policy-oriented climate science can best be understood within its political context. At an international level the IPCC has a pivotal role in the policy-making process, because its reports form the scientific basis for international climate negotiations. International politics thus have defined and organized the role that the IPCC plays in bridging over the interface between climate science and international climate politics. Two elements are key here. According to its political objectives and institutional configuration the IPCC is expected to deal in a particular way with scientific knowledge, uncertainties, and possible dissent, namely the "speaking consensus to power" approach (Van der Sluijs et al. 2010b). This approach can be distinguished from two 
other science-policy interface strategies to approach complex policy issues: the "speaking truth to power approach" and the "working deliberatively within imperfections" approach (see Box 1). The key question here is whether uncertainties are seen as a temporary lack of perfection in the knowledge (truth with error bars), as a problematic lack of unequivocalness (multiple contradictory truths), or as a fact of life (irreducible ignorance) - something that unavoidably plays a role in complex and politically sensitive topics.

\section{Box 1. Three policy strategies to deal with scientific uncertainties}

At the interface of science and policy one can look at scientific uncertainties in three different ways (Funtowicz 2006; Van der Sluijs 2006; Van der Sluijs et al. 2010a, 2010b). Each way leads to a different approach to uncertainties and each has its own drawbacks.

Approach 1: Uncertainty as imperfections in the knowledge: "truth with error bars."

One can first see uncertainty as a shortcoming in knowledge, where uncertainty is experienced as a temporary problem: just an imperfection in the science. The approach is to push back the uncertainty, among other things by creating increasingly complex models. As long as this is unsuccessful, the uncertainty is expressed numerically, for example an error bar around a best guess.

The related science-policy interface model is one that assumes a role of "speaking truth to power" and remaining imperfections captured in a quantified error bar. This approach runs into the limitation that by far not all uncertainties can be expressed quantitatively in a reliable way. What's more, in practice uncertainties do not become reduced with more research: the problem appears to become ever more complex. The drawback of this approach is that there is a semblance of certainty because the numbers coming from the increasingly complex models suggest that there is more knowledge than is actually the case.

Approach 2: Uncertainty as lack of unequivocalness: "consensus as proxy for truth."

The second vision sees uncertainty as a problematic lack of unequivocalness. One scientist says this, the other says that. It is un- 
clear who is right. The solution has been a comparative and independent evaluation of research results, aimed at building scientific consensus via multidisciplinary expert panels. This approach is geared toward generating robust findings.

The science-policy interface model is one that acknowledges that available knowledge is inconclusive and that the truth cannot yet be established - and it solves this limitation by assuming a role of "speaking consensus to power," where consensus is a proxy for truth and is established through a negotiated (among a broad group of peers) widely shared interpretation of the yet inconclusive body of scientific evidence. The drawback of this paradigm is that issues over which there is no consensus remain underexposed, whereas it is precisely this dissent that tends to be extremely relevant to policymaking.

Approach 3: Uncertainty and dissent as facts of life: "joint exploration of uncertainties and ignorance."

One can see uncertainty as a mere fact of life, something that unavoidably plays a role in complex and politically sensitive topics. We accept the fact that uncertainty and dissent are not temporary but permanent, and recognize that not all uncertainties can be expressed quantitatively. Such an approach demands a culture that is open to uncertainty and that recognizes that there are many things for which science cannot yet provide an answer. Ignorance and the influence of values are focused on here. Techniques applied to deal with it are knowledge quality assessment (Van der Sluijs et al. 2008) and risk management, including knowledge production, as deliberative or participative social processes. Robustness is sought here primarily in policy strategy and not in the knowledge base: which policy is useful regardless of which of the diverging scientific interpretations of the knowledge is correct.

The assumed science-policy interface model is one of "working deliberatively within imperfections" where scientists, policymakers, and other societal actors jointly explore the relevance of ignorance and uncertainties. The drawback of this approach is that uncertainty and minority interpretations are so much in the spotlight that we forget how much we do know about these risks and which items actually enjoy broad consensus. 
In terms of the strategies outlined in Box 1 , international politics established the IPCC mainly starting from the second vision about dealing with scientific uncertainties: creating a clear knowledge base on which to base international climate policy. The scientific reporting of the IPCC bases itself on the studies published, chiefly in peer-reviewed scientific journals. In this way, an attempt is made to get a sense of all the separate studies and to see what picture comes forward. IPCC reports aim to identify the state of knowledge while enjoying wide scientific support. This goal fosters developing consensus in the editorial teams. Exercising assessment through consensus is problematic though. For example, as a result of the IPCC consensus model weak signals (of possibly catastrophic climate risks) from the scientific community get a less prominent spot in the reports than they deserve based on their policy relevance. This is the case with tipping points: they can lead to severe non-linear impacts, but given the state of knowledge and the many uncertainties, univocal scientific consensus about the severity and scope of many of these tipping points cannot yet be reached (see also Van der Sluijs and Turkenburg 2006). Still, policymakers tend to experience this particular uncertainty as relevant in terms of policy: when designing a policy strategy you better have thought beforehand about extreme scenarios that cannot be ruled out but have an unknown chance of happening than be completely surprised if they occur unexpectedly at a later time (see also European Environment Agency [EEA] 2001). The consensus approach also deprives us of a full view of the plurality of scientific opinions within and between the various scientific disciplines that study the climate problem. It limits the political field of action on which players can present different scientific studies to substantiate their positions. For this reason, Pielke (2007) pleads for experts in the interface of science and policy to present themselves more as "honest broker(s) of policy alternatives" between pluralistic science and our pluralistic democratic society.

The recent IPCC reports also contain elements from the first and third approaches. Increasingly, in addition to a quantified uncertainty range around the presented figures (approach 1) we find a qualitative indication of the level of scientific understanding for each of the figures (approach 3). An example of this is the figures given for radiative forcing of the climate system. For a wide range of anthropogenic and natural forcing factors the IPCC presented a quantified uncertainty margin for each factor that has altered the temperature balance of Earth, and reports in addition an indication for the level of scientific 
understanding for each of those factors, which can be low, medium, or high. This acknowledges that high uncertainty does not necessarily imply low level of scientific understanding nor does high level of understanding automatically imply low uncertainty.

The IPCC's own guideline prescribes that any diverging scientific visions on certain aspects should be reported in the chapters that discuss those aspects. This does get done. However, in the policymakers' summaries, the technical summaries and the synthesis report of AR4 dissent is no longer discussed and only issues over which there is consensus are mentioned. Uncertainties are discussed though: the synthesis report of AR4 concludes with a chapter- "Robust Findings, Key Uncertainties" - that clearly indicates what robust conclusions there are and which aspects are still uncertain. The word "uncertainties" is also mentioned countless times in policymakers' summaries. Yet policymakers' summaries and synthesis reports do not provide insights into where in science is dissent and what positions are taken in this respect, whereas that information is indeed policy relevant. To get a good picture of it, one has to read the entire AR4.

\section{Discussion and Conclusion}

The scientific knowledge gathered and processed by the IPCC plays a primary role in the legitimation of domestic and international policy aimed at reducing greenhouse gas emissions. In turn, the long-term policy goals of the Framework Convention have become leading for the financing, organization and any questions surrounding a large portion of climate science. It is because of the central political role of the IPCC that precisely around the climate summit in Copenhagen (COP 15) the scientific debate flared up and became polarized. The central political role of science is the most important driving force behind the politicization of policy-oriented climate science.

Within the current national and international discussion about the IPCC there is relatively little attention being paid to this political context that shapes the role of the IPCC. This requires societal reflection on the role that the IPCC has been ascribed by the international political community in the interaction between climate science and climate policy. In the discussions following Climategate the emphasis was primarily on evaluating the procedures of the IPCC during the production of the fourth assessment report. Especially from a policy perspective, guaranteeing the scientific reliability of the IPCC report is 
indeed extremely important. In addition to attention for the procedures, societal reflection on the political role of the IPCC is also highly needed-specifically about the question of how the IPCC deals with scientific uncertainties and how it communicates with political bodies and society about it. To guarantee the policy relevance of the IPCC reports, politicians have opted for a consensus approach when dealing with scientific uncertainties. In other words, the IPCC is an institute framed by international politics, which had set up its procedures and practices from a specific vision on how politics deals with scientific uncertainties.

The current tendency to improve IPCC procedures via external evaluations fits with the current consensus approach: people are looking for ways to continue with the existing practices and legitimize them politically. It is also important to reflect on the strengths and weaknesses of the current consensus approach of the IPCC.

As mentioned, the political goal of the IPCC is to create a clear knowledge base. In this way the IPCC follows the second approach (see Box 1), whose strength is to shed light on scientific consensus. Such consensus can play a constructive role in legitimating policy. The disadvantage of the consensus approach is however that it underexposes scientific uncertainties and dissent, thus making the chosen policy - which, after all, wagers on consensus — vulnerable to scientific errors. The consensus approach cannot get along well with parts of the knowledge base where the state of scientific knowledge is still premature and univocal conclusions cannot be established along objective lines. The consensus approach also takes away a full perspective of the plurality of scientific views within and between the different scientific disciplines in relation to the climate problem. The consensus approach thus limits the political playing field in which players can present different scientific studies and subsequent perspectives for acting (policy options) to substantiate their positions.

This can be partially solved by building elements from the third approach into IPCC practices: explicit reflection on known and unknown unknowns and more openness for dissent in IPCC process and reporting. With very complex issues like climate change, uncertainties, interpretation options, ignorance, and possible surprises play a major role. To notice newly upcoming themes and weaknesses on time in everyday thinking, it is important not to reject diverging opinions immediately but to actually pay specific attention to them (see EEA 2001; Van der Sluijs 2007). Climate skeptics and other scientists who think differently than the mainstream on certain points can fulfill 
a counter-expertise function in the scientific and political debate about climate change. To this end it is recommended to include a dissent chapter in the synthesis report of the IPCC, which contains a sketch of minority scientific views and points of ongoing scientific dispute. The summary for policymakers should also have a section about dissent. This would include claims that the problem is less severe as well as warnings that the problem is more severe than the picture that arises from the wide consensus side. Both dissent contributions could constitute a first step to give critical voices a more visible place in AR5 than they had in AR4 in terms of wide agreement. By exercising more openness about scientific uncertainties, ignorance, and dissent, policymakers get a more complete picture of climate science and its limitations. Instead of choosing the optimal policy based on the widest scientific consensus interpretation, they can design robust and flexible policy strategies that take into account uncertainty and plurality in science. Robust strategies are packages of policy measures that are useful regardless of which of the competing scientific interpretations might be right or the direction in which the uncertainties are going. Flexible strategies are those that can be quickly adjusted to advancing scientific insights, in which locking-in and irrevocability of implemented policy trajectories can be prevented. Such policy strategies are less vulnerable to uncertainty and to the question of whether the IPCC has identified the problems correctly and faultlessly (Dessai and Van der Sluijs 2007).

The third approach also has a clear drawback: an overexposure of dissent and uncertainty, which in practice often seems to undermine the basis for political policymaking because measures are postponed in order to wait for an increased certainty, which does not arrive. Approach 3 requires science to be more open about uncertainties, boundaries of knowledge, and plurality of conflicting yet tenable scientific interpretations. From politicians and policymakers this approach demands that they be more aware of the limitations of science and the nature of the uncertainties surrounding climate change. It is however of great importance that politicians do not hide endlessly behind those scientific uncertainties but take their own political responsibility.

A plea to give a more visible place to voices from, among others, climate-skeptic scientists, also demands a slightly different role from climate skeptics. Climate-skeptic scientists follow chiefly the third approach: they want more attention for scientific uncertainties. To that end, some of them have currently organized themselves separately and publish their own reports presenting mainly those studies that rela- 
tivize or contradict the main conclusion of the IPCC. As mentioned, this is a potentially useful form of counter-expertise.

The way in which climate skeptics relate to the scientific debate could strongly improve though. A difficult point is that there is a broad spectrum of climate skepticism (which also applies, by the way, to climate activism), varying from criticism to and alternative interpretations of data that are scientifically sound to obvious urban legends. In a more extensive overview of skeptical visions it is often difficult to determine which arguments are or are not useful. Further, arguments are sometimes repeated for years on end, even when the errors have been pinpointed and sometimes even recognized by the corresponding skeptic. This is frustrating for mainstream and skeptic climate scientists alike. Mainstream scientists can get tired of having to keep reacting to the same, by now settled point of skepticism. And climate skeptics often say that they are ignored when climate scientists no longer react to their arguments. In short: the high scientific standards that climate skeptics rightly demand from the IPCC apply to them too.

Jeroen P. van der Sluijs, PhD, is senior researcher at the Copernicus Institute, Utrecht University. His work focuses on those situations where scientific assessment is used as a basis for policymaking on environmental risks before conclusive scientific evidence and scientific consensus are available on the causal relationships, the magnitude, and the probabilities of these risks. His work seeks to understand and improve the science-policy interface in a context of scientific controversy and uncertainty by contributing and applying deliberative methods and tools for knowledge quality assessment. He has published sixty-five journal articles and contributed twenty-five chapters to edited volumes. Address: Department of Innovation, Environmental and Energy Sciences Copernicus Institute of Sustainable Development, Utrecht University, Budapestlaan 6, 3584 CS Utrecht, The Netherlands. E-mail: j.p.vandersluijs@uu.nl.

\section{References}

Avery, George H. 2010. "Scientific Misconduct: The Perversion of Scientific Evidence for Policy Advocacy." World Medical \& Health Policy 2 (4): Article 3.

- 2011. "Scientific Misconduct: A Response to Davies and Fielding." World Medical \& Health Policy 3 (2): Article 12.

Clark, William C., and Jill Jäger. 1997. "The Science of Climate Change." Environment 39 (9): 23-28. 
Dessai, Suraje, and Jeroen P. van der Sluijs. 2007. Uncertainty and Climate Change Adaptation: A Scoping Study. Report NWS-E-2007-198, Department of Science Technology and Society, Copernicus Institute, Utrecht University.

Doran, Peter T., and Maggie Kendall Zimmerman. 2009. "Examining the Scientific Consensus on Climate Change." EOS, Transactions American Geographical Union 90 (3): 22-23.

European Environment Agency (EEA). 2001. Late Lessons from Early Warnings. The Precautionary Principle 1896-2000. Copenhagen: European Environment Agency. http://www.eea.europa.eu/publications/environmental_issue_report_ 2001_22 (accessed 11 January 2012).

Funtowicz, Silvio O. 2006. "Why Knowledge Assessment?" Pp. 138-145 in Interfaces between Science and Society, ed. Ângela Guimarães Pereira, Sofia Guedes Vaz, and Sylvia Tognetti. Sheffield, UK: Green Leaf Publishing.

Funtowicz, Silvio O., and Jerome R. Ravetz. 1986. "Policy-Related Research: A Notational Scheme for the Expression of Quantitative Technical Information." Journal of the Operational Research Society 37 (3): 243-247.

-1990. Uncertainty and Quality in Science for Policy. Dordrecht: Kluwer. 1993. "Science for the Post-Normal Age." Futures 25 (7): 735-755.

Gleick, Peter. 2007. Testimony to the Senate Committee on Commerce, Science, and Transportation for the Hearing on Climate Change Research and Scientific Integrity February 7, 2007 Threats to the Integrity of Science. Oakland, CA: Pacific Institute.

Heartland. 2009. "Events." http://www.heartland.org/events/NewYork09/proceedings .html (accessed 1 November 2011).

Hoggan, James. 2009. Climate Cover-Up: The Crusade to Deny Global Warming. Vancouver, BC: Greystone Books.

Intergovernmental Panel on Climate Change (IPCC). 1990. Climate Change: Scientific Assessment. Contribution of Working Group I to the First Assessment Report of the Intergovernmental Panel on Climate Change. Cambridge, UK: Cambridge University Press.

- 1996. Climate Change 1995: The Science of Climate Change. Contribution of Working Group I to the Second Assessment Report of the Intergovernmental Panel on Climate Change. Cambridge, UK: Cambridge University Press.

- 2001. Climate Change 2001: The Scientific Basis. Contribution of Working Group I to the Third Assessment Report of the Intergovernmental Panel on Climate Change. Cambridge, UK: Cambridge University Press.

_. 2006. "Principles Governing IPCC Work." Intergovermental Panel on Climate Change, Geneva. http://www.ipcc-wg1.unibe.ch/procedures/PrinciplesProcedur esGoverningIPCC.pdf (accessed 11 January 2012).

- 2007. Climate Change 2007: The Physical Science Basis. Contribution of Working Group I to the Fourth Assessment Report of the Intergovernmental Panel on Climate Change. Cambridge, UK: Cambridge University Press.

Idso, Craig, and Siegfried F. Singer. 2009. Climate Change Reconsidered: 2009 Report of the Nongovernmental International Panel on Climate Change (NIPCC). Chicago, IL: Heartland Institute.

InterAcademy Council. 2010. Climate Change Assessments Review of the Processes and Procedures of the IPCC. Amsterdam: InterAcademy Council. http:// reviewipcc.interacademycouncil.net/report.html (accessed 11 January 2012). 
Irwin, Alan. 2001. Sociology and the Environment. Cambridge, UK: Polity Press.

Jasanoff, Sheila, Gerald E. Markle, James C. Petersen, and Trevor J. Pinch, eds. 1995. Handbook of Science and Technology Studies. A Thousand Oaks, CA: Sage.

Jasanoff, Sheila, and Brian Wynne. 1998. "Science and Decision Making." Pp. 1-87 in Human Choice and Climate Change: The Societal Framework, ed. Steve Rayner and Elizabeth Malone. Columbus, OH: Battelle Press.

Kuhn, Thomas. 1962. The Structure of Scientific Revolutions. Chicago, IL: University of Chicago Press.

McCright, Aaron M., and Riley E. Dunlap. 2003. "Defeating Kyoto: The Conservative Movement's Impact on U.S. Climate Change Policy." Social Problems 50 (3): 348-373.

McKitrick, Ross, ed. 2007. Independent Summary for Policymakers of IPCC Fourth Assessment Report. Vancouver, BC: Fraser Institute. http://www.uoguelph.ca/ $\sim$ rmckitri/research/ispm.html (accessed 11 January 2012).

Michaels, David. 2005. "Doubt Is Their Product. Industry Groups Are Fighting Government Regulation by Fomenting Scientific Uncertainty." Scientific American 292 (6): 96-101.

Oreskes, Naomi. 2004. "Beyond the Ivory Tower: The Scientific Consensus on Climate Change." Science 306 (5702): 1686-1686.

- 2007. "The Scientific Consensus on Climate Change: How Do We Know We're Not Wrong?" Pp. 65-100 in Climate Change: What It Means for Us, Our Children, and Our Grandchildren, ed. Joseph F.C. DiMento and Pamela M. Doughman. Cambridge, MA: MIT Press.

Oreskes, Naomi, and Erik Conway. 2010. Merchants of Doubt, How a Handful of Scientists Obscured the Truth on Issues from Tobacco Smoke to Global Warming. New York: Bloomsbury.

Parson, Edward A. 1995. "Integrated Assessment and Environmental Policy Making, In Pursuit of Usefulness." Energy Policy 23 (4/5): 463-476.

Peiser, Benny J. 2005. "The Dangers of Consensus Science." National Post (Canada), 17 May. http://ff.org/centers/csspp/library/co2weekly/2005-06-09/dangers.htm (accessed 31 March 2012).

Petersen, Arthur C. 2006. Simulating Nature: A Philosophical Study of Computer-Simulation Uncertainties and Their Role in Climate Science and Policy Advice. Apeldoorn, the Netherlands: Spinhuis. http://hdl.handle.net/1871/11385 (accessed 11 January 2012).

Petersen, Arthur C., Albert Cath, Maria Hage, Eva Kunseler, and Jeroen P. van der Sluijs. 2011. "Post-Normal Science in Practice at the Netherlands Environmental Assessment Agency." Science Technology \& Human Values 36 (3): 362-388.

Pielke, Roger A., Jr. 2005. "Consensus About Climate Change?" Science 308 (5724): 952-953.

- 2007. The Honest Broker. Cambridge, UK: Cambridge University Press.

Pilson, Michael E.Q. 2006. "We Are Evaporating our Coal Mines into the Air." Ambio 35 (3): 130-133.

Ravetz, Jerome R. 1999. "What Is Post-Normal Science?" Futures 31 (7): 647-653.

Richardson, Katherine, Will Steffen, and Diana Liverman. 2009. Climate Change Global Risks: Challenges \& Decisions. Synthesis Report, University of Copenhagen. http://climatecongress.ku.dk/pdf/synthesisreport (accessed 11 January 2012). 
Singer, Siegfried F., ed. 2008. Nature, Not Human Activity, Rules the Climate: Summary for Policymakers of the Report of the Nongovernmental International Panel on Climate Change. Chicago, IL: Heartland Institute.

Social Learning Group. 2001. Learning to Manage Global Environmental Risks: A Comparative History of Social Responses to Climate Change, Ozone Depletion and Acid Rain. Vols. 1 and 2. Cambridge, MA: MIT Press.

Van der Sluijs, Jeroen P. 1997. "Anchoring amid Uncertainty; On the Management of Uncertainties in Risk Assessment of Anthropogenic Climate Change." PhD Diss., Utrecht University.

- 2006. "Uncertainty, Assumptions, and Value Commitments in the KnowledgeBase of Complex Environmental Problems." Pp. 67-84 in Interfaces Between Science and Society, ed. Ângela Guimarães Pereira, Sofia Guedes Vaz, and Sylvia Tognetti. Sheffield, UK: Green Leaf Publishing.

- 2007. "Uncertainty and Precaution in Environmental Management: Insights from the UPEM conference." Environmental Modelling \& Software 22 (5): 590598.

- 2010. "Uncertainty and Complexity: The Need for New Ways of Interfacing Climate Science and Climate Policy." Pp. 31-49 in From Climate Change to Social Change: Perspectives on Science: Policy Interactions, ed. Peter Driessen, Pieter Leroy, and Wim van Vierssen. Utrecht: International Books.

Van der Sluijs, Jeroen P., Matthieu Craye, Silvio Funtowicz, Penny Kloprogge, Jerome Ravetz, and James Risbey. 2005. "Experiences with the NUSAP System for Multidimensional Uncertainty Assessment in Model Based Foresight Studies." Water Science and Technology 52 (6): 133-144.

Van der Sluijs, Jeroen P., Arthur C. Petersen, Peter H.M. Janssen, James S. Risbey, and Jerome R. Ravetz. 2008. "Exploring the Quality of Evidence for Complex and Contested Policy Decisions." Environmental Research Letters 3 (2). http:// iopscience.iop.org/1748-9326/3/2/024008 (accessed 11 January 2012).

Van der Sluijs, Jeroen P., and Wim C. Turkenburg. 2006. "Climate Change and the Precautionary Principle." Pp. 245-269 in Implementing The Precautionary Principle, Perspectives and Prospects, ed. Elizabeth Fisher, Judith Jones, and René von Schomberg. Cheltenham, UK: Edward Elgar.

Van der Sluijs, Jeroen P., Rinie van Est, Monique Riphagen. 2010a. Room for Climate Debate, Perspectives on the Interaction Between Climate Politics, Science and the Media. Den Haag, the Netherlands, Rathenau Instituut. http://www.rathenau .nl/uploads/tx_tferathenau/Room_for_climate_debate.pdf (accessed 11 January 2012).

— 2010b. "Beyond Consensus: Reflections from a Democratic Perspective on the Interaction Between Climate Politics and Science." Current Opinion in Environmental Sustainability 2 (5/6): 409-415.

Van der Sluijs, Jeroen P., Josée C.M. van Eijndhoven, Brian Wynne, and Simon Shackley. 1998. "Anchoring Devices in Science for Policy: The Case of Consensus Around Climate Sensitivity." Social Studies of Science 28 (2): 291-323. 